\title{
Sebastian, König von Portugal [Sebastião, Rei de Portugal] (1824) de Carl Weisflog: história e mito numa novela romântica "fantasiosa" ao gosto Biedermeier
}

\author{
Ana Maria Ramalheira \\ Universidade de Aveiro - CLLC
}

Resumo: Considerado um epígono de E.T.A. Hoffmann, em cujo círculo de amigos era conhecido pelo seu humor e apurada veia satírica, o escritor tardio e juiz Carl Weisflog (1770-1828) é autor do conjunto de narrativas e de novelas, publicadas entre 1924 e 1929, em doze volumes, com o título genérico de Phantasiestücke und Historien, pela então famosa casa editora Arnold (Dresden). Correspondendo genericamente ao gosto literário burguês da época, esta obra conheceu na altura uma considerável fortuna editorial. 0 presente artigo debruça-se particularmente sobre Sebastian, König von Portugal (1824), uma narrativa constante do 2. - volume da referida colectânea de Weisflog, baseada na figura do jovem rei de Portugal e no percurso labiríntico do pretenso D. Sebastião que apareceu Veneza. Nesta novela histórica, um interessante exemplo de Unterhaltungsliteratur, entrecruzam-se elementos da Romantik, com manifestas influências de E.T.A. Hoffmann, e da Literatura do Biedermeier, elementos esses que sobrelevam especialmente do processo de ficcionalização a que a matéria história em apreço foi submetida, incluindo da empatia emocional suscitada pelas figuras do poeta épico Camões e do rei D. Sebastião, cujo patriotismo fervoroso deve ser enquadrado na procura de um Nationalgeist que a Alemanha, na altura tão dividida, ansiava para si própria.

Palavras-chave: mito, D. Sebastião, identidade 


\begin{abstract}
Often regarded as a successor of E.T.A Hoffmann, known among his circle of friends for his humorous ways and acute satirical insight, the late judge and writer, Carl Weisflog (1770-1828), is the author of a few narratives and novellas, published between 1924 and 1929, in twelve volumes, bearing the generic title of Phantasiestücke und Historien, and published by the renowned Arnold publishing house in Dresden. In an attempt to comply with the customary bourgeois literary taste of the time, in due process, this piece of writing generated a considerable editorial fortune. The essay under review attempts to focus on, in particular, Sebastian, König von Portugal (1824), a narrative included in the second volume of the aforementioned collection by Weisflog, based on the figure of this young king of Portugal and in the labyrinthic path followed by the alleged King Sebastian, who was said to have appeared in Venice. Elements of the Romantik along with manifest influences of E.T.A. Hoffmann as well as those of the Literature of the Biedermeier have blended into this historical novella, which has been widely considered an intriguing specimen of Unterhaltungsliteratur. Understandably, these elements were underscored during the process of fictionalization, especially these historical materials and the ensuing treatment they had been subjected to, along with the emotional empathy aroused by the figures of the epic poet Camões and King Sebastian. Such a patriotic fervor, nontheless, should be framed within the search for a Nationalgeist, which Germany, divided, at the time, longed for itself.
\end{abstract}

Keywords: myths, King Sebastian, identities

Considerado um epígono de E.T.A. Hoffmann (1776-1822), em cujo círculo de amigos era conhecido pela sua apurada veia satírica, o escritor tardio e juiz Carl Weisflog (1770-1828) viu publicada a sua obra Phantasiestücke und Historien [Textos Fantasiosos e Histórias], ${ }^{1}$ um conjunto de cerca de 50 novelas (incluindo históricas), narrativas e poemas, pela então famosa casa editora Arnold de Dresden, entre 1924 e $1929 .{ }^{2}$ Correspondendo genericamente ao gosto literário burguês da época, os doze volumes que integram esta coletânea conheceram na altura uma considerável fortuna editorial. Ao longo do século XIX a obra foi alvo de sucessivas edições, integrais ou parciais, acompanhadas de enorme repercussão na imprensa periódica alemã: ${ }^{3}$ em 1825 pela editora de A. F. Macklot (Estugarda), em 1927 pela casa editora vienense Lechner, em 1929, pela Kornicker (Estugarda), ${ }^{4}$ em 1839 de novo pela Arnold (que inclui uma resenha biográfica do escritor, seguida de um conjunto de cartas por este dirigidas ao seu editor), em 1868 pela Helfer 
(Dresden) e ainda em antologias várias, juntamente com narrativas de outros autores (cf. Goedeke, 1905: 510-511). Em 1922, o historiador da Literatura e bibliófilo Carl Georg von Maassen (1880-1940) dá à estampa uma seleção destas narrativas com o título Bürgerliche Historien [Histórias Burguesas] para a coleção "Die Bücherei der neuen Serapionsbrüder", sob a chancela da editora Georg Müller, de Munique. Algumas das narrativas que integram Phantasiestücke und Historien foram ainda publicados em várias antologias e objeto de diversas edições avulsas, algumas das quais até de luxo. Embora hoje praticamente esquecidas, muitas novelas de Carl Weisflog integraram, ainda em vida do autor, importantes coleções literárias, como as "Meyers National-Bibliothek Deutscher Klassiker" (vol. 46), "Miniatur-Bibliothek der deutschen Classiker" (vol. 140), "Groschenbibliothek" (vol. 115), entre outras. Vieram igualmente a lume umas quantas publicações bibliófilas contendo algumas narrativas, tais como, entre outras, Das große Los [A Grande Sorte], em cem exemplares numerados e editados pelo escritor, tradutor e escritor austríaco Gustav Meyrink (München, Weber, 1925), e a narrativa Biographische Spittelfreuden des abgesetzten Privatschreibers Jeremias Kätzlein [Prazeres Biográficos de Hospital do deposto Escriba Privado Jeremias Kätzlein], com desenhos de Carl Spitzweg (Lorch, Bürger, 1948). Com efeito, Das große Los, talvez a novela mais conhecida de Carl Weisflog, e Biographische Spittelfreuden des abgesetzten Privatschreibers Jeremias Kätzlein, uma narrativa epistolar dirigida a E.T.A. Hoffmann, foram as obras mais editadas do deste escritor alemão. ${ }^{5}$

Conhecido no círculo de amigos dos reputados escritores E. T. A. Hoffmann (17761822) e de Karl Wilhelm Salice-Contessa (1777-1825) pelo seu agradável sentido de humor, Carl Weisflog nasceu na cidade de Sagan, então integrada no condado prussiano de Sprottau e, desde 1947, incorporada na Polónia. ${ }^{6}$ Formou-se em Direito em Königsberg, onde frequentou os seminários de Kant, e estagiou em Tilsit e Memel. Regressou a Sagan em 1802 na qualidade de juiz, tendo sido nomeado em 1827 director do tribunal municipal (Stadtgerichtsdirektor). Em Sagan, onde casou, terá dedicado horas de lazer à música (chegou mesmo a compor pequenas peças musicais e até uma ópera),,$^{7}$ à floricultura (cultivava tulipas no seu jardim) ${ }^{8}$ e a um convívio social calmo e prazenteiro (cf. Ellinger 1910; Wachsmann 1939: 233 ss.). 
Carl Weisflog começou a escrever tardiamente, apenas aos 50 anos de idade, após ter conhecido E.T.A. Hoffmann, que lhe fora apresentado no Verão de 1819 pelo seu amigo Karl Wilhelm Salice-Contessa, durante uma estada nas termas de Warmbrunn (cf. Koning 1989: 147-149). Como o próprio Weisflog fez questão sublinhar na supramencionada narrativa epistolar com que abre a sua coletânea, E.T.A. Hoffmann fora quem despertara nele a veia literária adormecida (cf. Weisflog 1824: Bd. 1: 14 ss). Weisflog admite ainda desassombradamente que as Phantasiestücke de Hoffmann "à maneira de Callot" tinham exercido uma influência determinante na elaboração, ainda que "à sua maneira", das Phantasiestücke und Historien (cf. Weisflog 1924, Bd. 1: 15). 0 já então famoso mestre da Literatura fantástica, por seu turno, nunca mencionou Weisflog em qualquer dos seus escritos, incluindo nas três cartas que enviou a amigos berlinenses durante a referida estada naquela estância termal (cf. Weidmann 1923: 13). ${ }^{9}$

0 facto de Weisflog ter começado a escrever tardiamente foi em grande parte compensado pelo diligente empenho com que se dedicou à atividade literária. Na verdade, em apenas oito anos, o juiz/escritor silesiano produziu as cerca de 3.300 páginas que integram os 12 volumes da coletânea Phantasiestücke und Historien. Uma parte substancial destas narrativas foram inicialmente publicadas com regularidade no periódico literário Abendzeitung, pela mão do seu editor, o escritor, tradutor e crítico Theodor Hell (pseudónimo do Conselheiro Carl Gottfried Theodor Winkler [1775-1856]), que exercia grande influência nos círculos literários da época. ${ }^{10}$ Weisflog, que terá enviado a Theodor Hell os seus primeiros textos em Novembro de 1821, dedica reconhecidamente ao seu editor o poema que serve e preâmbulo a Phantasiestücke und Historien (vd. Weisflog 1924, Bd. 1: 3-4).

$\mathrm{Na}$ terceira década do século XIX, Weisflog era, com efeito, um dos escritores silesianos mais conhecidos na Alemanha e os seus livros, que aparentemente se vendiam como pãezinhos quentes, eram lidos por pessoas de todas as classes sociais, incluindo estudantes, burgueses e aristocratas. Não obstante a enorme repercussão que as Phantsiestücke und Historien tiveram na imprensa periódica literária da época, e apesar de alguns dos temas neles explorados estarem na génese de algumas farsas do famoso 
dramaturgo e actor austríaco Johann Nestroy, ${ }^{11}$ a verdade é que a obra de Weisflog depressa caiu no esquecimento, não tendo logrado suscitar atenção dos investigadores literários ao longo de quase um século. Em 1923 (curiosamente, cerca de um século após a primeira edição de Phantsiestücke und Historien) vieram a lume duas dissertações sobre a produção literária de Weisflog: uma da autoria de Hans Schmalfuß, sobre a vida e obra do escritor (cf. Schmalfuß 1923), e a outra, assinada por Walter Weidemann, sobre as relações do escritor com E.T.A. Hoffmann (cf. Weidemann 1923). A obra de Weisflog foi objeto, desde 1989, de um conjunto de artigos (assaz repetitivos, diga-se de passagem) do investigador holandês Henk J. Koning, que incidem principalmente sobre a influência de E.T.A. Hoffmann nas Phantsiestücke und Historien e sobre a contaminação de temas e motivos desta coletânea em peças mágicas e farsas de Nestroy (cf. Koning 1989; 1990; 1992; 1994; e 2012).

Ao longo das cerca de 20 páginas da referida narrativa epistolar na primeira pessoa que abre a coletânea, em jeito de prefácio, Weisflog apresenta uma espécie de programa poético. 0 escriba sexagenário Jeremias Kätzlein, o alter ego de Weisflog, dirige-se num tom reverencial ao grande escritor romântico que falecera pouco tempo antes, em 1822, sublinhando a forte influência que este exercera na sua obra. Admitindo que não estava ao nível do génio que ressuma de Der goldene Topf [0 Pote de Ouro], Prizessin Brambilla [Princesa Brambilla] e Meister Floh [Mestre Pulga], Jeremias Kätzlei/Weisflog, que manifestamente não deseja ser considerado um mero epígono de Hoffmann, distancia-se contudo do tom arrepiante e amargo das narrativas do seu Prosper Alpanus, ${ }^{12}$ que, na sua opinião, denunciaria um escárnio profundamente encoberto, um desdém pelas pessoas e um menosprezo pelos seus interesses mais sagrados (cf. Weisflog 1924, Bd. 1: 15, 25-26). Weisflog considera que da sua própria obra, pelo contrário, emerge alegria, leveza, benevolência e uma consciência clara que nunca se degrada numa aniquilação espiritual medonha, sublinhando ainda que os momentos de entretenimento que dela ressumam levam todos a sorrir, pois, mesmo quando são trocistas e incisivos, e nunca chegam a provocar verdadeira dor, ainda que possam provocar algumas lágrimas de tristeza (cf. ibidem). Esta conceção de humor de Weisflog, aliás consentânea com a mundividência afeta 
à época do Biedermeier - caracterizada pela representação de um mundo poético alheado da turbulência política, mais virado para "os bons velhos tempos", para a esfera do privado e para o convívio social em círculos mais pequenos e restritos ${ }^{13}$ - é ainda clarificada na sua narrativa Hobelspäne [Aparas]:

Die Andere [Art des Humors] und die bei weitem Bessere, ist die Gemütliche. Hierzu gehört mehr als Witz, Scharfsinn und Zusammenstellung der Contraste. Hierzu gehört Herz und Seele.

[A outra (forma de humor) e de longe a melhor é a do aconchego convivial. Vai além da piada, da argúcia e da conjugação dos contrastes. Ela inclui coração e alma.] (Weisflog 1824, Bd. 4: 209)

Ainda que numa carta datada de 22 de Julho de 1823, Weisflog se queixasse a Theodor Hell de que não lhe agradava ceder ao gosto do público feminino dos livros de bolso, alertando para o perigo de o seu esforço poder ter um efeito perverso, na medida em o que subsistiria acabava por ser lido apenas uma única vez (cf. Weisflog 22.06.1823: 277278), tudo leva a crer contudo que o escritor silesiano não se terá esforçado muito por impedir que os seus leitores vertessem algumas lágrimas. Com efeito, no perfil de Weisflog que traçou para a Allgemeine Deutsche Biographie, Georg Ellinger considera que o juiz/escritor de Sagan, apesar de tudo, não apresenta quaisquer afinidades intelectuais com E.T.A. Hoffmann, pois aquilo que deste tomara de empréstimo terá sido mais colado exteriormente do que processado interiormente (cf. Ellinger 1910: 373).

A fábula de Sebastião, Rei de Portugal, com que enceta o 2. volume de Phantasiestücke und Historien (1824, Bd. 2: 1-147), é inspirada na vida do rei D. Sebastião e no aparecimento, no ano de 1595, do chamado D. Sebastião de Veneza, que a historiografia de referência identificou como sendo o calabrês Marco Túlio Catizone (cf. D’Antas, 1866: 251 ss.). ${ }^{14}$ A imbricada ação da narrativa de Weisflog é susceptível de ser dividida, grosso modo, em oito partes, correspondentes aos diferentes espaços em que ela se desenrola: Portugal, Marrocos, montanhas do Atlas, Monte Sinai (no Egipto), Amhara (na Etiópia), Veneza, Nápoles e S. Lúcar de Barremeda (em Espanha).

Na longínqua Lusitânia, o reino de Portugal e do Algarve, cheio de árvores de fruta e de flores, onde as pessoas são agradáveis e herdeiras de um passado glorioso, reina 
o jovem D. Sebastião, cujo "coração cheio do fogo da religião, de sede de sabedoria, de feitos e dos lindos sonhos do mundo da poesia, era alheio ao amor pelas mulheres". ${ }^{15}$ Depois de ler Os Lusíadas, o rei, educado e incentivado pelos padres jesuítas a combater os mouros infiéis, resolve tirar o pobre poeta Camões da miséria, pedindo-lhe que seja seu amigo e professor. Vindo da ilha vulcânica de Estromboli, situada ao norte da costa da Sicília, aparece, de repente, Marco Tullio Cotizone, que é fisicamente um sósia perfeito de D. Sebastião. Os traços mefistofélicos desta figura sobrelevam do seu fato negro, da faixa vermelha cor de sangue, traçada do ombro ao quadril e do barrete de veludo preto de onde pende um tufo de penas de galo vermelhas de sangue (cf. Weisflog 1824, Bd. 2: 31-32). 0 "cavaleiro negro" (der schwarze Ritter), como é reiteradamente apelidado pelo narrador omnisciente, torna-se amigo inseparável do rei e incentiva-o à conquista da Mauritânia, uma empresa apoiada pelo Grande Inquisidor, que considera ser um dever levar a cruz de Cristo àquela região. Contrariando todos os seus conselheiros, incluindo Camões, que vê em Catizone uma cobra, D. Sebastião decide partir para África. Ajoelhando-se perante o velho poeta "venerável" (ehrwürdig), "devoto" (fromm) e "consagrado" (gottgeweiht), o jovem monarca pede-lhe a bênção. Camões finca no peito do rei os "dedos incandescentes" (die glühenden Finger), um gesto que leva Catizone a afastar de imediato o poeta, ameaçando-o com uma espada (cf. Weisflog 1824, Bd. 2: 57).

No final da guerra santa entre cristãos e muçulmanos, que é pormenorizadamente relatada, D. Sebastião é salvo por Catizone, que surge de novo de repente montado num dromedário e acolitado por seis mouros. 0 rei é por este levado para as montanhas do Atlas, mais propriamente para o castelo do mágico Mogreby, onde não há rosas, mas apenas espinhos. Mogreby - o fiel servo de satanás dos contos da mil e uma noites ${ }^{16}$ - persegue almas para as devorar. Marco tenta, em vão, convencer o rei a regressar a Portugal para juntar um novo exército a fim de reconsquistar o reino aos espanhóis. D. Sebastião opta todavia por peregrinar por África, a fim de expiar a culpa que sentia pelo desastre de Alcácer Quibir e pelas suas consequências para o seu povo. No Monte Sinai, num mosteiro de monges maronitas preguiçosos e falsos, um velho sábio fala-lhe da existência de Amhara. ${ }^{17} \mathrm{O}$ rei resolve ir então para Amhara, que se avistava ao longe por uma faixa azul 
(ein blauer Streif [ibidem: 86]) desenhada pelas suas montanhas. Nesta bela, civilizada e paradisíaca "terra da paz, da amizade e do amor" (Land der Ruhe, der Freundschaft und der Liebe [ibidem: 123]), reiteradamente comparada com Portugal, onde todos viviam numa harmonia consentânea com a verdadeira religião de Cristo, D. Sebastião acaba por casar com a bela Ahmerine, a filha do rei, com quem tem três filhos. Num momento de felicidade, o monarca lusitano recorda com saudade a sua pátria, o seu professor Camões, que já não viveria, e o seu amigo de juventude Marco Catizone. Como que por magia, no preciso momento em que é invocado, este último aparece. Critica o rei por ter abandonado o seu povo há desanove anos, acabando por convencê-lo a regressar a Portugal para vingar o sangue derramado em Alcácer Quibir. Na viagem de regresso, em Veneza, D. Sebastião é preso, julgado ao longo de três anos e finalmente levado para Nápoles por traidores ao serviço do rei de Espanha. Apesar de ser reconhecido pelo conde de Lemos como sendo o verdadeiro rei de Portugal, acaba por ser confundido com o impostor Catizone, que ali havia sido condenado às galés uns meses antes. Enviado para Espanha, e julgado de novo pelo tribunal da Santa Inquisição, D. Sebastião recusa retractar-se, acabando por revelar o sinal sagrado que lhe tinha sido feito no peito por Camões, o grande poeta lusitano que estaria no céu ao lado de Petrarca, Homero e Dante. Como que por magia, Marco Catizone aparece de novo de repente, e pede a D. Sebastião que se desdiga para dar tempo a que muitos milhares de portugueses cheguem a S. Lúcar de Barremeda para o salvar. 0 rei acusa Catizone de traição e, no momento em que lhe mostra o sinal sagrado que Camões lhe deixara no peito, o cavaleiro negro agiganta-se até ao tecto e os seus seguidores transformam-se em corvos, dragões e cães com cabeças de homem, que riem, pulam e emitem silvos estridentes. D. Sebastião ainda ataca o gigante, morrendo todavia na esperança de vir ainda a encontrar-se com Ahmerine, com os seus filhos e com Camões.

Ao interesse de Carl Weisflog na figura de D. Sebastião não será de todo alheia a curiosidade suscitada nos círculos intelectuais alemães em torno da figura do rei a quem o grande poeta Camões dedicara a epopeia Os Lusíadas. Com efeito, no início do século XIX, são publicadas as primeiras versões integrais alemãs de Os Lusíadas, uma [1806-1807] assinada por Carl Christian Heise (1772-1809) e a outra (1807) por Friedrich Adolph Kuhn 
(1774-1844) e Carl Theodor Winkler (ou seja, Theodor Hell, o supramencionado amigo e editor de Carl Weisflog). Curiosamente, Kuhn e Winkler foram dois dos mais destacados implusionadores (juntamente com Friedrich Kind) do Dresdner Liederkreis, uma famosa sociedade literária, que, com a já mencionada Abendzeitung, inaugurou em 1814 o período Biedermeier na "Florença do Elba", tendo igualmente exercido um papel muito importante na dinâmica cultural da cidade por cerca de três décadas. ${ }^{18}$ Não terá sido talvez por acaso que o Künstlerdrama [drama de artista] Camoens (1832), um dos primeiros textos ficionais alemães que apresenta Camões e D. Sebastião como figuras principais, tivesse sido escrito pelo então jovem escritor, tradutor e jornalista Wilhelm Theodor von Chézy (1806-1865), que na altura vivia em Dresden, frequentava o Dresdner Liederkreis e era um leitor assíduo da Abenzeitung. ${ }^{19}$ Há de facto indícios vários que levam a crer que as figuras de Camões e de D. Sebastião suscitavam de algum modo, na altura, o interesse de diversos intelectuais que frequentavam o Dresdner Liederkreis. Curiosamente, entre os frequentadores deste círculo contava-se igualmente Ludwig Tieck (1773-1853), que em 1843 viria a publicar a Künstlernovelle romântica Tod des Dichter [Morte do Poeta], cujo protagonista, o poeta Camões, morre ao mesmo tempo que o seu rei e senhor D. Sebastião e, concomitantemente, que a própria pátria que ele cantara. Foi ainda em Dresden que Tieck conhecera em 1828 Adelheid Reinbold (1800-1839), autora de König Sebastian, oder Wunderbare Rettung und Untergang [Rei D. Sebastião ou Regate Prodigioso e Declínio] (1839), um extenso romance sobre D. Sebastião, publicado sob o pseudónimo masculino de Franz Berthold e editado pelo próprio Tieck, que também fez questão de assinar o longo prefácio.

Weisflog tende a intensificar a verosimilhança na sua novela histórica D. Sebastião, Rei de Portugal através do recurso a notas de rodapé, que remetem reiteradamente não só para a Portugiesische Geschichte [História Portuguesa] (1759), de Georg Christian Gebauer (1690-1773), ${ }^{20}$ mas também para outras obras, igualmente citadas por este historiógrafo alemão, que relatam muitas das anedotas em torno de D. Sebastião,21 por sua vez submetidas por Weisflog a um emaranhado processo de ficcionalização. Aliás, numa carta que enviou a Theodor Hell em 1822, Weisflog sublinhava precisamente o caráter histórico da sua novela: "Sebastian ist rein geschichtlich. Hier ist alles verbrieft, und wahrlich, so ist 
Alles gewesen! Wo die Phantasie nachgeholfen, das brauche ich nicht erst zu bemerken." [Sebastião é puramente histórico. Aqui está tudo documentado e, realmente, tudo se passou assim! E onde entra a fantasia não necessito sequer de referir.] (Weisflog 1839: 252).

A ação, que apresenta semelhanças estruturais com o Stationendrama [drama de estações], desenrola-se em espaços diversos, entre os quais na África longínqua e estranha. As abundantes e coloridas descrições da natureza, fonte de tiradas fantasiosas, por vezes até piegas aos olhos do leitor hodierno, reflectem sempre o estado de alma de D. Sebastião. Este deleita-se com paisagens em estado natural à boa maneira de Rousseau, sintónicas com a sua mundividência genuinamente cristã e com a sua nobreza de caráter. A sintaxe actancial assenta numa relação de contraste, quase a preto e branco, distinguindo-se entre as personagens moralmente bem formadas, independentemente de serem cristãs ou muçulmanas, como Camões, D. Sebastião, o rei mouro e as gentes de Amhara, e as malévolas ou demoníacas, como Marco Catizone, o rei de Espanha, os Jesuítas e os Inquisidores. ${ }^{22} \mathrm{D}$. Sebastião é o joguete cobiçado na guerra eterna entre o bem e o mal, que encontra respectivamente nas figuras de Camões e de Marco Tullio Catizone os seus principais representantes. A narrativa histórica fantasiosa em apreço apresenta de facto alguns traços da chamada Schwarze Romantik [Romantismo Negro], de que E.T.A. Hoffmann foi talvez o expoente máximo, na configuração das forças irracionais e demoníacas, que são amiúde atraídas por forças magnéticas (Catizone justifica as suas aparições repentinas, alegando que tinha sido movido pela força de um íman [cf. Weisflog 1824, Bd.1: 106]), que comunicam por telepatia e que se transformam em animais aterradores. ${ }^{23}$

O motivo do duplo é usado no sentido de levar a ação para a esfera do horror. Catizone, a encarnação do diabo, e as figuras fantasmagóricas que o acompanham, tão ao gosto de E.T.A. Hoffmann, tendem a emaranhar a fábula e a criar arrepios no leitor, reforçando assim a tensão dramática da diegese. Enquanto Hoffmann exige muito do leitor devido à imbricada teia de relações, por vezes até bastante confusa, que cria entre as suas personagens, Weisflog denuncia a função da figura do duplo satânico de D. Sebastião logo que a personagem entra em ação. Da cena final da narrativa, em que D. Sebastião é submetido a um longo e doloroso processo de tortura física e psicológica, e em que o pavor 
é intensificado com a transformação fantasmagórica de Catizone e dos seus acólitos, sobrelevam também claras ressonâncias hoffmannianas, principalmente do romance Die Elixiere des Teufels (1815-1816) e do Nachtstück [quadro nocturno] Ignaz Denner (1817).

0 fervor patriótico de D. Sebastião, a sua sede de aventura e o deambular em peregrinação constituem igualmente traços típicos do Romantismo. 0 rei é uma espécie de Wanderer [viandante] que, na sua viagem de estação em estação sem destino, acaba por deparar-se com um novo começo, ainda que relativamente efémero. 0 seu processo de transformação ontológica culmina na longínqua e paradisíaca Amhara, a terra da paz, reiteradamente associada à côr azul - distinguia-se ao longe pela faixa azul das suas montanhas (vd. supra) e D. Sebastião recorda "a lonjura azul, onde vivia Ahmerine e as crianças" [die blaue Ferne, wo Ahmerine und die Kinder wohnten (Weisflog 1824, Bd.1: 115). Os espaços euforizantes Amhara e Portugal - que contrastam com as outras estações, manifestamente disfóricas, por onde vai peregrinando D. Sebastião - são associados ao tom azul, partilhando ambos as montanhas azuis e o céu azul. ${ }^{24}$ Com efeito, a famosa flor azul do romance inacabado Heinrich von Ofterdingen (1802) de Novalis (pseudónimo de Georg Philipp Friedrich von Hardenberg, 1772-1801) ou o poema "Die blaue Blume" (1818) [A flor azul] de Joseph von Eichendorff (1788-1857) tornaram as flores e a tonalidade azul símbolos do amor, da nostalgia romântica, do anseio pelo infinito, bem como de uma fusão saudável entre homem e natureza, entre perceções sensoriais e níveis de conhecimento.

O valor simbólico de Amhara é obviamente comparável ao do mito da utópica e enigmática Atlântida, explorado também por Hoffmann em diversas obras, incluindo em Der goldne Topf. Ao contrário das personagens complexas e interiormente dilaceradas de Hoffman, que acabam por ter com Atlântida uma relação problemática, a figura real de D. Sebastião mantém sempre com Amhara, onde impera o verdadeiro Cristianismo, consubstanciado numa harmonia mítica sagrada entre o homem bom e tolerante e a natureza bela e generosa, uma relação muito pacífica.

A mitificação da poesia como algo de sagrado (Camões é o poeta enviado por Deus que salva o rei com a sua bênção) e a poetização do mito do paraíso cristão (que Amhara simboliza) constituem uma espécie de apelo às forças originais do bem. De facto, na 
supramencionada carta, datada de 10 de Maio de 1822, Weisflog explica ao seu editor o simbolismo do já referido gesto da bênção de Camões a D. Sebastião antes da partida para Alcácer Quibir: “Die letzte diesfällige Szene mit Camoens aber ist Werk der Dichtung und die 'glühenden Finger' eine Hyperbel oder Metonymie und will sagen: die glühende Seele Camoens strömte aus seinen Fingern auf Sebastian's Brust." [A última cena a este respeito com Camões é todavia obra da poesia e os "dedos incandescentes" uma hipérbole ou metonímia que quer dizer: a alma escaldante de Camões fluiu dos seus dedos para o peito de D. Sebastião.] (Weisflog 1939: 254). Sublinhe-se ainda que Abdel Melek, o nobre e sábio rei mouro que derrota D. Sebastião em Alcácer Quibir, apela igualmente às forças do bem no discurso que profere antes da batalha a fim de motivar as suas tropas (cf. Weisflog 1824, Bd. 2: 61-62).

Ao contrário dos finais em aberto, interrogativos e sobrecarregados de perplexidade que sobrelevam das narrativas de E.T.A. Hoffmann, o final apesar de tudo feliz da Historie em análise de Weisflog terá agradado ao público-leitor burguês da época. Ao abdicar da felicidade plena em Amhara numa derradeira tentativa de libertar o seu povo do jugo castelhano, ao entregar-se heroicamente à morte, negando retractar-se e expiando assim a sua culpa com elevada nobreza de caráter, D. Sebastião acaba por reconquistar a dignidade perdida. Com efeito, numa carta a Theodor Hell datada de 23 de Abril de 1822, Weisflog referia-se da seguinte forma a Sebastian, König von Portugal, que já teria enviado ao seu amigo editor:

Sebastian ist eine Tragödie, in der ersten Potenz, das heißt: 1) es waltet nicht rein das Schicksal, sondern die Handlung, und die Katastrophe entwickelt sich aus dem Inneren des Herzens. 2) Die Darstellung hat moralische und ästhetische Motive und Zwecke. Das Gefühl der Pflicht führt in ein Labyrinth, es stürzt hier in gräßliches Verderben, aber es erhebt auch am Ende, als das einzig Haltbare, über die Trümmer alles Erdenglücks und ist das Oriflamm in der letzten Stunde.

[Sebastião é uma tragédia, o que, em primeira instância, significa: não reina apenas o destino, mas também a ação, e a catástrofe desenvolve-se a partir do interior do coração. 2) A representação tem motivos e objetivos morais e estéticos. 0 sentido do dever conduz a um labirinto, precipita-se aqui em terrível ruína, mas também se levanta no final, como se fosse a única coisa que permanecesse dos 
destroços toda a felicidade terrena, sendo no último momento a chama de ouro.] (Weisflog 1839: 252).

Esta observação de Weisflog, associada ao seu manifesto interesse por temas históricos, não deixa margem para dúvidas sobre o enquadramento desta narrativa na Literatura do Biedermeier: é o sentimento de dever de D. Sebastião que impulsiona a catástrofe em Alcácer Quibir e que, ao mesmo tempo, o leva a peregrinar para expiar a sua culpa, a valorizar a paz interior e os pequenos momentos de felicidade e ainda a enfrentar a morte com uma dignidade redentora. É da exemplar atitude de D. Sebastião, da sua renúncia, da sua resignação e principalmente do seu fervoroso e inabalável patriotismo que ressumam os supramencionados motivos e objetivos morais e estéticos desta narrativa.

Muito embora não subsistam quaisquer provas do envolvimento de Weisflog nas chamadas Guerras de Libertação (Befreiungskriege), que entre 1813 e 1815 puseram fim à hegemonia francesa de Napoleão Bonaparte em grande parte do continente europeu, a aventura trágica de Alcácer Quibir, por um lado, e o fervor patriótico de Camões e de D. Sebastião, por outro, acabam por entroncar numa intensa atividade editorial na época da Restauração que manifestava não só o desencanto perante os ideais da Revolução Francesa, mas também as aspirações revolucionárias nacionalistas no sentido de uma Alemanha unificada. Com efeito, a Época da Restauração, no período que medeia entre o Congresso de Viena, em 1815, e a Revolução de Março (Märzrevolution), em 1848, ficou marcada por diversas reacções artísticas às mudanças políticas e sociais, designadamente pela corrente conservadora do Biedermeier, pelos liberais da Jovem Alemanha (Junges Deutschland) e pelos democratas politicamente mais radicais da época anterior à Revolução de Março (Vormärz). 0 desencanto e as esperanças frustradas do Junges Deutschland, bem como o facto de muitos se terem agarrado à velha ordem dos príncipes alemães redundaram finalmente na Revolução de Março.

Se, por um lado, em Sebastian, König von Portugal, o exemplar fracasso da aventura temerária e trágica do rei de Portugal remete para um certo desencanto político e uma certa desconfiança em relação a mudanças revolucionárias, pouco consentâneas aliás com o modus vivendi burguês, calmo e prazenteiro do juiz e escritor de Sagan, por outro lado, o 
profundo e genuíno fervor patriótico partilhado por D. Sebastião e por Camões, o poeta que imortalizou o seu povo, aponta para uma tendência, aliás também típica da Literatura alemã do Biedermeier, para harmonizar o conflito entre o mundo real e o mundo ideal, entre tensões políticas e o poder salvífico e gregário do Nationalgeist [espírito de nação], que um poema épico como Os Lusíadas também consubstanciaria.

O universo diegético da novela Sebastian, König von Portugal integra personagens e acontecimentos consentâneos com as obras historiográficas indicadas em notas de rodapé, ainda que obviamente submetidos a um elaborado processo de ficcionalização, em especial intensificado na parte da trama narrativa que é encetada com o desenlace da batalha de Alcácer Quibir. A fusão de pessoas e de eventos históricos e fictícios, incluindo o mito sebastianista do rei redivivo, redunda numa interessante teia de relações entre estas duas variáveis (cf. Nünning 1995: 46) da qual ressuma também o código ideológico subjacente à Literatura alemã do Biedermeier. O que sobreleva da novela histórica de Weisflog em apreço é a ênfase na paz, na harmonia, na tranquilidade e nas virtudes burguesas conservadoras de raiz cristã da moderação, da modéstia e da discrição, não obstante a presença dos elementos demoníacos, geralmente evitados na Literatura do Biedermeier. Sebastian, König von Portugal constitui de facto um interessante exemplo de Unterhaltungsliteratur [Literatura de entretenimento] ${ }^{25}$ ao gosto Biedermeier, do qual transpira em última instância a intenção de estimular um Nationalgeist unificador, que a Alemanha na altura territorial e politicamente tão dividida ansiava para si própria. 


\section{Bibliografia}

\section{Textos e cartas}

Camões, Luís de [1806-1807], Die Lusiaden, Heldengedicht von Camoens aus dem Portugiesischen übersetzt von Dr. C[arl] C[hristian] Heise, Hamburg/Altona, Gottried Vollmer.

-- (1804), "Camoens", traduções de August Wilhelm Schlegel, in Schlegel, A. W., Blumensträusse italienischer, spanischer und portugiesischen Poesie, Berlin, Realschulbuchhandlung, p. 199-225.

-- (1807), Die Lusiaden des Camoens, aus dem Portugiesischen in deutsche Ottawereime übersetzt, Leipzig, Weidmannische Buchhandlung.

Berthold, Franz [Pseudónimo de Adelheid Reinbold] (1838), König Sebastian, oder Wunderbare Rettung und Untergang, hg. von Ludwig Tieck, Dresden/Leipzig, Arnoldische Buchhandlung.

Chézy, Wilhelm Theodor von (1832), Camoens. Trauerspiel in fünf Acten, Bayreuth, Verlag der Grau `schen Buchhandlung.

Schlegel, Friedrich (1962), "An Camöens", in S., F., Dichtungen (Friedrich Schlegel, Kritische Ausgabe seiner Werke, Bd. V), hg. von Hans Eichner, München/Paderborn/Wien, Schöning, p. 311.

Tieck, Ludwig (1834), “Tod des Dichters”, in T., L., Novellenkranz. Ein Almanach auf das Jahr 1834, Berlin, Reimer, p. 1-347.

-- (1944), A Morte de Camões, tradução do alemão de Maria Osswald, Lisboa, Avis.

Verfasser der graue Mappe [Pseudónimo] (1802), “Die Geschichte von Mogreby”, in V.d.g.M. (1802-1803), Phantasus. Tausend und ein Märchen, 4 Bde, Berlin, Johann Gottfried Braun, Erster Band, p. 297-647.

Weisflog, Carl (1824-1829), Phantasiestücke und Historien, 12 Bde, Dresden, Arnoldische Buchhandlung.

-- (1824), “Biographische Spittelfreuden des abgesetzten Privatschreibers Jeremias Kätzlein an den königl. preußischen Kammergerichtsrath E.T.A. Hoffmann im Dschinnistan, zwei 
Treppen hoch, vorn heraus", in W., C. (1824-1829), Phantasiestücke und Historien, Bd. 1, p. 6-30.

-- (1839), “Carl Weisflog über sich selbst. Mitgetheilt aus dessen Briefen an Th. Hell”, in W., C., Phantasiestücke und Historien, Dresden/Leipzig, Arnoldische Buchhandlung, 2. Aufl., Bd. XII, p. 240-317.

-- (1824), “Sebastian, König von Portugal”, in W., C. (1824-1829), Phantasiestücke und Historien, Bd. 2, p. 1-147.

\section{Estudos, obras de consulta e bases de dados}

[Anónimo] (1830), "Karl Weisflog”, in Neuer Nekrolog der Deutschen, 6. Jg. 1828, 2. Teil, Voigt, Ilmenau, p. 575-576.

Bayer-Schur, Barbara (2007), “Ansichten von den Nachtseiten der Romantik. Zur narrativen Funktion der Naturwissenschaften in E.T.A. Hoffmanns Der Magnetiseur", in E.T.A. Hoffmann Jahrbuch, Berlin, Erich Schmidt Verlag, Bd. 15, p. 50-76.

Bark, Joachim (2001), Biedermeier und Vormärz. Bürgerlicher Realismus, Stuttgart, Klett 2001 [= Geschichte der deutschen Literatur, Bd. 3].

Bouterwek, Friedrich (1805), Geschichte der portugiesischen Poesie und Beredsamkeit (Geschichte der Poesie und Beredsamkeit seit dem Ende des 13. Jahrhunderts, Bd. IV), Göttingen, Johann Friedrich Röwer.

D’Antas, Miguel (1866), Les Faux D. Sébastien. Étude sur l'Histoire de Potugal, Paris, Auguste Durand, Libraire.

Ellinger, Georg (1910), "Weisflog, Karl”, in Allgemeine Deutsche Biographie (ADB), Leipzig, Duncker \& Humblot, Bd.55, p. 372-375, URL: http://www.deutschebiographie.de/pnd11727786X.html?anchor=adb (Consultado em Novembro de 2015).

Engel, Manfred (2011), "Vormärz, Frührealismus, Biedermeierzeit, Restaurationszeit? Komparatistische Konturierungsversuche für eine konturlose Epoche", Oxford German Studies, 40, p. 210-220. 
Foltin, Hans Friedrich (1965), "Die minderwertige Prosaliteratur. Einteilung und Bezeichnung", Vierteljahrsschrift für Literaturwissenschaft und Geistesgeschichte [DVjs], Jg. 39, p 288-323.

Goedeke, Karl (1905), Grundriss zur Geschichte der deutschen Dichtung aus den Quellen, Nach dem Tod des Verfassers in Verbindung mit Fachgelehrten fortgeführt von Edmund Goetze, Achtes Band (Vom Weltfrieden bis zur französischen Revolution 1830), Dresden, Akademie Verlag / Verlag von L. Ehlermann, p. 506-511.

Der graue Mappe [Pseudónimo] (1802), "Die Geschichte von Mogreby", in Phantasus. Tausend und ein Märchen, Erster Band, Berlin, Johann Gottfried Braun, p. 297-406.

Hempel, Dirk (2008), Literarische Vereine in Dresden. Kulturelle Praxis und politische Orientierung des Bürgertums im 19. Jahrhundert, Tübingen, Max Niemeyer Verlag.

Hitzig, Julius Eduard (1839), E. T. A. Hoffmanns Leben und Nachlass, 2 Bde. Stuttgart, Fr. Brodhagische Buchhandlung, dritte vermehrte und verbesserte Auflage, Mit Kupfern. [1823].

Koning, Henk J. (1992), “Carl Weisflog”, in Killy, Walther (Hrsg.), Literatur Lexikon. Autoren und Werke deutscher Sprache, 15 Bde, Gütersloh, Bertelsmann Lexikon Verlag, Bd. 12, p. 216.

-- (1992a), “Carl Weisflog (1770-1828) - ein Biedermeierautor aus Sagan”, in Bein, Werner (Hrsg.), Sagan und Sprottau in der schlesischen Geschichte, Würzburg, Bergstadtverlag Wilhelm Gottlieb Korn-Stiftung Kulturwerk Schlesien, p. 91-97.

-- (1994), “Carl Weisflog. Ein Epigone E.T.A. Hoffmanns”, in E.T.A. Hoffmann. Jahrbuch, Bd. 2, Berlin, Erich Schmidt Verlag, p. 100-115.

-- (1989), "Carl Weisflog (1770-1828). Ein schlesischer Biedermeierschriftsteller in den Spuren E.T.A. Hoffmanns", Schlesien, 3, p. 146-161.

-- (2012), "Carl Weisflog (1770-1828). Ein vergessener schlesischer Nachfolger E.T.A. Hoffmanns und ein Stofflieferant Johann Nestroys", in Bialek, Eduard (Hrsg.), Schlesien Erlesen: Aufsätze zur Literatur des 18. Und 19. Jahrhunderts. Festgabe für Monika Taubitz zum 75. Geburtstag, Dresden, Neisse Verlag, p. 51-77. [2004].

-- (1990), "Carl Weisflog und Johann Nestroy", Nestroyana. Blätter der Internationalen 
Nestroy-Gesellschaft, Bd. 10, 3/4, p. 38-54.

Kosch, W. (1958), "Weisflog, Karl”, in Deutsches Literatur-Lexikon. Biographischbibliographisches Handbuch, Begr. von W. K., 4 Bde., 2. vollständig neubearb. und stark erw. Aufl., Bern, A. Francke Verlag, 4. Bd., p. 3270.

Martins, Catarina (2000), “Camões como paradigma do artista na novela Tod des Dichters de Ludwig Tieck", in M., C. / Garraio, Júlia, Camões na Alemanha. A Figura do Poeta em Obras de Ludwig Tieck e Günter Eich, Coordenação de M. M. G. Delille, Coimbra, Livraria Minerva/Centro Interuniversitário de Estudos Germanísticos, p. 49-186.

Martins, Catarina / Garraio, Júlia (2000), “Momentos da recepção de Camões na literatura de expressão alemã (séculos XIX e XX)”, in M., C. / G., J., Camões na Alemanha. A Figura do Poeta em Obras de Ludwig Tieck e Günter Eich, p. 13-44.

Nünning, Ansgar (1995), Von historischer Fiktion zu historiographischer Metafiktion, 2 Teile, Teil 1: Theorie, Typologie und Poetik des historischen Romans, Trier, Wissenschaftlicher Verlag Trier.

Ramalheira, Ana Maria Pinhão (2002), Alcácer Quibir e D. Sebastião na Alemanha. Representações Historiográficas e Literárias (1578-ca.1800) [+CD-ROM com Apêndice Documentais], Coimbra, MinervaCoimbra / Centro Interuniversitário de Estudos Germanísticos / Universidade de Aveiro.

Salomon, Gerhard (1983), E.T.A. Hoffmann. Bibliographie, Mit Abbildungen, Hildesheim/Zürich/New York: Georg Olms Verlag.

Schlegel, Friedrich (1803), "Beiträge zur Geschichte der modernen Poesie und Nachricht von provenzalischen Manuskripten", Europa, I-2, p. 49-71.

-- (1958), “Die Gechichte der europäischen Literatur (1803-1804)”, in S., F., Wissenschaft der europäischen Literatur. Vorlesungen, Aufsätze und Fragmente aus der Zeit von 1795-1804 (Friedrich Schlegel, Kritische Ausgabe seiner Werke, Bd. XI), hg. von Ernst Behler, München/Paderborn/Wien, Schöningh, p. 1-188.

Schmalfuß, Ernst (1923), Carl Weisflog. Ein biographischer Versuch, Dissertation, Leipzig, 1923.

Schmitz, Walter (1997), "Romantik in Dresden”, in Literatur, Kunst und Musik. 2. Bayrisch- 
sächsischer Germanistenkongreß 13.-15.10.1994 in Dresden, Dokumentation, Hg. von der Akademie für Lehrerfortbildung Dillingen in Zusammenarbeit mit dem Deutschen Germanistenverband (Landesverbände Sachsen und Bayern) (= Akademiebericht Nr. 302), p. 139-158.

Wachsmann, Carl Adolf von (1939), "Carl Weisflog, biographisch skizzirt von C. v. Wachsmann", in W., Carl, Phantasiestücke und Historien, 12 Bde, Dresden/Leipzig, Arnoldische Buchhandlung, 2. Aufl., Bd. 12, p. 227-239.

Weidemann, Walter (1923), Carl Weisflogs Beziehungen zu E.T.A. Hoffmann, Dissertation, Perleberg.

Wilmsmeier, Wilhelm (1913), Camoens in der deutschen Dichtung des 19. Jahrhunderts. Ein Beitrag zum Künstler-Drama, Dissertation, Münster.

Cf. WordCat [s./d.], URL: http://www.worldcat.org/identities/lccn-no2002-59455/ (Consultado em Novembro de 2015). 
Ana Maria Ramalheira é Professora Auxiliar da Universidade de Aveiro (UA), onde exerce funções docentes nas áreas da Literatura, Cultura e Língua Alemãs. Foi membro do Centro Interuniversitário de Estudos Germanísticos (CIEG, Univ. de Coimbra) desde a sua fundação até ao final de 2007, data a partir da qual passou a integrar o Centro de Línguas, Literaturas e Culturas (CLLC) da UA. Licenciou-se em Línguas e Literaturas Modernas (variante Inglês/Alemão) pela Universidade de Coimbra, onde obteve também o grau de Mestre em Literatura Comparada com uma dissertação sobre a recepção portuguesa dos dramas Die Mutter e Der kaukasische Kreidekreis de Bertolt Brecht. Doutorou-se na UA com a tese Alcácer Quibir e D. Sebastião na Alemanha. Representações Historiográficas e Literárias (1578-ca.1800). Tem desempenhado vários cargos institucionais, sendo actualmente diretora do Curso de Mestrado em Línguas e Relações Empresariais da UA, diretora da RUA-L. Revista da Universidade de Aveiro-Letras e membro do Conselho de Curadores da Fundação Marion Ehrhardt. Entre as suas diversas publicações, maioritariamente na área da recepção e imagologia literárias, contam-se a referida tese de doutoramento (Coimbra: MinervaCoimbra / Centro Interuniversitário de Estudos Germanísticos / Universidade de Aveiro, 2002, 783 p.) e a co-autoria das obras Do Pobre B.B. em Portugal (Aveiro: Estante Editora, 1991) e Portugal-Alemanha: Memórias e Imaginários (1.ํvol.: Da Idade Média ao Século XVIII e 2. vol.: Séculos XIX e XX (Coimbra: MinervaCoimbra / CIEG, 2007 e 2010, respectivamente). 


\section{NOTAS}

${ }^{1}$ São apenas traduzidos, além das citações, os títulos das obras alemãs referidos no texto propriamente dito do presente artigo.

2 Passo a citar as narrativas de Weisflog a partir da primeira edição de Phantasiestücke und Historien (Weisflog, 1824-1829).

${ }^{3}$ Sobre a recepção crítico-valorativa, não consensual, às primeiras edições de Phantasiestücke und Historien, vd. Goedeke 1905: 510-511; Schmalfuß 1923: 105-134.

${ }^{4}$ Esta edição abre com uma carta de Jean Paul, datada de 12 de Setembro de 1829, em que este responde negativamente ao pedido que lhe terá sido endereçado pelo editor, Dr. Morvell [W.F.A. Vollmer], no sentido de elaborar um prefácio para a edição em apreço de Phantasiestücke und Historien (cf. Weisflog 1829: 5, 7-15). Esta carta é seguida de uma outra, fictícia, de E.T.A. Hoffmann, sem indicação de lugar e de data (cf. ibidem: 1626). Sobre o caráter fictício desta carta, vd. Salomon 1983: 58.

5 De acordo com o WorldCat, uma base de dados bibliográfica que abrange catálogos online de milhares de bibliotecas em todo o mundo, as Phantasiesstücke und Historien foram alvo de, pelo menos, 26 edições em língua alemã entre 1824 e 1990. Cf. WordCat [s./d.].

${ }^{6}$ Sobre a vida e obra de Carl Weisflog, vd., entre outros, Schmalfuß 1923; [Anónimo], 1828; Goedeke 1905; Ellinger 1910; Wachsmann 1939; Kosch 1958; e Koning 1992: 216.

${ }^{7}$ Weisflog tocava muito bem piano, tendo mesmo chegado a compor a ópera Die Beiden Marseiller, que não se sabe se terá sido publicada ou representada (cf. Wachsmann 1839: 233). Sobre a atividade de Weisflog como compositor, vd. Schmalfuß 1923: 94 ss.

${ }^{8}$ Muitas das suas narrativas, como, entre outras, Die Geschichte der Zitter-Pappel (Populus tremula). Eine botanische Mythe e Eps, der Zwiebelkönig, apresentam descrições detalhadas e interessantíssimas de flores, de frutos, de árvores e de jardins.

${ }^{9}$ De facto, apesar de E.T.A. Hoffmann não ter dado grande importância a este encontro com Weisflog, o seu amigo Julius Eduard Hitzig (juiz, editor e escritor) deu conta deste convívio na sua conhecida biografia do famoso escritor romântico (cf. Hitzig 1839: 111).

${ }^{10} \mathrm{Na}$ Abendzeitung colaboravam na altura igualmente, além Theodor Hell e Carl Weisflog, Fridrich de la Motte Fouqué, Ernst von Houwald, os dois irmãos Salice-Contessa, designadamente Karl Wilhelm e Christian Jacob, entre muitos outros.

${ }^{11}$ Por exemplo, Der böse Geist Lumpazivagabundus oder Das liederliche Kleeblatt (representada em Viena em 1833 e publicada em 1835), Die Familien Zwirn, Knieriem und Leim oder Der Welt-Untergangs-Tag N. 34 - 06/ 2016 | 297-320 - ISSN 1645-1112 | http:/dx.doi.org/10.21747/16451112/litcomp34a19 317 
(representada em 1834) e Der Feenball oder Tischler, Schneider und Schlosser (publicada em 1833). Cf. Koning 1990: 39-52; 2012: 75-76.

12 O mágico Prosper Alpanus é uma personagem do conto maravilhoso Klein Zaches, genannt Zinnober (1818), de E.T.A. Hoffmann, por sua vez inspirada no mágico Próspero da peça A Tempestade, de Shakespeare.

${ }^{13}$ Sobre a Literatura alemã do Biedermeier, vd., entre outros, Bark 2001; Engel 2011.

${ }^{14}$ Sintomaticamente, o pretenso D. Sebastião de Veneza apareceu no mesmo ano em que morreu em Paris D. António, Prior do Crato, candidato ao trono de Portugal e o mais forte opositor ao domínio espanhol. Sobre os falsos D. Sebastião, vd. a obra de referência de Miguel D’Antas (1866).

15 "Ganz erfüllt vom Feuer der Religion, vom Durst nach Weisheit und Thaten und von den schönen Träumen der Dichterwelt, blieb diesem Herzen Weiberliebe fremd." (Weisflog 1824, Bd. 2: 31).

16 Weisflog terá lido decerto o conto maravilhoso "Die Geschichte von Mogreby" sobre o mágico Mogreby, constante da obra Phantasus. Tausend und ein Märchen, assinada sob o pseudónimo por Verfasser der graue Mappe (1802).

17 Trata-se, de facto, de uma das nove regiões étnicas (kililoch) da Etiópia. Inclui o Parque Nacional Simien, onde se encontra o ponto mais elevado da Etiópia. Os habitantes de Ahmara, tradicionalmente a principal tribo da Etiópia, são cristãos, na sua maioria ligados à Igreja Ortodoxa etíope. A língua amhárica é semítica, de algum modo relacionada com o árabe e com o hebreu. Amhara é hoje um das regiões mais pobres da Etiópia. Numa carta datada de 10 de Maio de 1822, igualmente dirigida ao seu editor, Weisflog enfatiza o caráter heteroreferencial desta novela, a propósito da verdadeira existência de Amhara, não obstante o processo de semantização a que o espaço foi submetido: "Das Reich Amhara existirt wirklich und ist wirklich ein Christenstaat, der jetzt den Wanderern unzugänglich ist. Ich hab's gelesen, aber schon lange, und weiß unglücklicherweise nicht mehr, wo. Aber den Namen wenigstens finden Sie im Conversationslexicon im Artikel Afrika. Das Uebrige bei der Sache ist Werk der Phantasie." [0 reino de Amhara existe realmente e é de facto um país cristão, que agora está inacessível aos viandantes. Li isto, há já muito tempo, mas infelizmente já não sei onde. Mas pelo nome pode encontrá-lo no Dicionário de Conversação, no artigo relativo a África. 0 resto na obra é trabalho da imaginação.] (Weisflog 1839: 254).

18 Ao contrário de outros círculos literários mais informais, frequentados por escritores e artistas do Romantismo alemão, o Liederkreis de Dresden integrava as pessoas educadas no meio da nobreza da côrte da Residenzstadt, tendo sido pioneiro na tendência na transformação de convívios literários em práticas sociais da burguesia (cf. Hempel 2008: 60). Sobre a influência cultural do Dresdner Liederkreis, vd. Hempel 2008: 55 ss.; e Schmitz 1997.

N. ${ }^{\circ} 4$ - 06/ 2016 | 297-320 - ISSN 1645-1112 | http:/dx.doi.org/10.21747/16451112/litcomp34a19 
${ }^{19}$ A supramencionada versão integral em língua alemã da epopeia portuguesa por Kuhn \& Winkler inclui no prefácio uma resenha da vida de Camões, por sua vez bastante apoiada, entre outras, numa súmula biográfica do poeta elaborada pelo lusitanista Friedrich Bouterwek (1766-1828), na sua Geschichte der portugiesischen Poesie und Beredsamkeit (1805: 142-211). Já em 1803, o dramaturgo e poeta Friedrich Schlegel havia publicado na revista Europa o famoso artigo "Beiträge zur Geschichte der modernen Poesie und Nachricht von provenzalischen Manuskripten", uma entusiástica resenha da vida e obra de Camões (vd. Schlegel 1803). Curiosamente, no retrato que aqui faz de Camões, Schlegel apresenta-o em primeira instância como herói e patriota e só em segunda instância como poeta. A mencionada versão integral de Os Lusíadas de Heise abre com um poema dedicado ao grande poeta português ("Wie Göttern biet'ich dir die eignen Gaben"), que creio ser um dos primeiros testemunhos de recepção produtivo no espaço de língua alemã (cf. Camões [18061807]: 2-6). Friedrich Schlegel fala sobre Camões nas "Wiener Vorlesungen" (1812), sublinhando, no contexto da guerra contra Napoleão, os elementos nacionalistas e patrióticos de Os Lusíadas (cf. Schlegel 1958: 158). Um dos primeiros exemplos de recepção produtiva do famoso poeta épico português na Alemanha é soneto "An Camöens" (1807), de Friedrich Schlegel (publicado de novo em 1823, nas suas Sämtliche Werke), em cujo último terceto o autor dá a entender que tencionava escrever um poema épico nacional alemão: Sei, Camöens, denn mein Vorbild! Laß mich 'es wagen / Des Deutschen Ruhms Urkunde aus den Wogen / Empor zu halten, an die Rettung glaubend." [Sê, Camões, o meu modelo! Leva-me a ousar / Elevar das ondas o monumento da glória alemã / Acreditando na salvação] (Schlegel 1962: 311). August Wilhelm Schlegel partilhou do interesse do seu irmão por Camões, tendo inclusivamente dado à estampa nos seus Blumensträusse italienischer, spanischer und portugiesischen Poesie versões alemãs do Canto VI de Os Lusíadas, de dois sonetos e de outros poemas de Camões (cf. Schlegel 1804: 199-225). Sobre a recepção de Camões na Alemanha do século XIX, vd. o estudo pioneiro de Wilmsmeier (1913) e o de Martins \& Garraio (2000: 15-48), este um dos mais recentes. Sobre o início da recepção de Os Lusíadas na Alemanha em finais do século XVIII e a concomitante chamada de atenção para o génio de Camões e para a figura e o mito de D. Sebastião, o jovem rei a quem o grande poeta dedica a epopeia dos portugueseses, vd. Ramalheira 2002: 624-642.

${ }^{20}$ Sobre a recepção da figura e do mito de D. Sebastião nesta obra historiográfica de Georg Christian Gebauer, vd. Ramalheira 2002: 497-544.

${ }^{21}$ Além de citar reiteradamente Gebauer, Weisflog remete também, entre outras obras, para Historiae Sui Temporis (1604-1608), de Jacques Auguste de Thou, para Historia de Bello Africano (1580), de Fr. Luis Nieto (que Weisflog confunde com Johann Thomas Freigius, o autor alemão da versão latina da famosa relação da batalha do monge dominicano espanhol), para Raisons d'État \& Reflexions Politiques sur l'Histoire \& Vies des Roys de Portugal (1670), de Ferdinand de Galardi, e para Histoire Général de Portugal (1735), de Nicolas de La Clède. Sobre a recepção alemã da batalha de Alcácer Quibir e da figura de D. Sebastião no século XVII, vd. Ramalheira 2002: 321-377.

N.ํ 34 - 06/ 2016 | 297-320 - ISSN 1645-1112 | http:/dx.doi.org/10.21747/16451112/litcomp34a19 
22 O monarca castelhano é reiteradamente apresentado com traços demoníacos: “Aber im spanischen Nachbarlande lauerte schon der Verderber, der unerstättlich nach dem schönen portugal lechzte. Es war der kalte und unmenschliche Philipp II., der Philipp, der seinen ehrwürdigen Vater, den großen Carl V., noch im Grabe beschimpfte" [Mas na vizinha Espanha já farejava o anti-Cristo, que insaciavelmente aspirava pelo belo Portugal. Era o frio e desumano Filipe II, o Filipe que destratava o seu venerável pai, o grande Carlos V, quando este ainda estava no túmulo] (Weisflog 1824, Bd. 2: 14).

${ }^{23}$ Sobre ímanes e forças magnéticas naturais na obra de E.T.A Hoffmann, vd., por exemplo, Bayer-Schur 2007.

${ }^{24} \mathrm{O}$ cometa que é uma premonição da desgraça de Alcácer surge no céu azul de Portugal ("Da stand im Azurblau des Himmels der strahlende Komet”, Weisflog 1824, Bd. 2: 64-65).

${ }^{25}$ De acordo com o contestado modelo tripartido de Hans Friedrich Foltin, baseado em critérios de qualidade estética dificilmente destrinçáveis, a Unterhaltungsliteratur situar-se-ia num plano intermédio entre a Hochliteratur [Literatura erudita] e a Trivialliteratur [Literatura trivial]. Cf. Foltin 1965: passim. 